\title{
O Comércio Ambulante nos Trens de São Paulo: Sociabilidade e Conflito ${ }^{1}$
}

\author{
Natália Cruz Sousa²
}

\section{Resumo}

O trabalho tem como cenário os trens de São Paulo, onde circulam milhares de pessoas diariamente. $O$ estudo desenvolvido parte da percepção da dinâmica dos trens enquanto espaço de sociabilidade e conflito, observada na pesquisa de campo realizada na Linha 11 do trem de São Paulo, do trecho Luz a Guaianazes, com atenção as relações sociais tecidas entre os atores: ambulantes, passageiros, pedintes, e agentes de segurança. A pesquisa foi construída com objetivo de evidenciar e analisar a prática do comércio ambulante, e suas implicações no espaço onde prática é proibida pelo poder público, mas que pode ou não ser desejável por parte dos passageiros, tornando necessário aos ambulantes estratégias e desenvolvimento de astúcias cotidianas para a permanência no espaço. Contudo, problematizo a respeito da relação entre ambulantes e passageiros através da comparação estabelecida com outra prática dita irregular no espaço, a mendicância. A temática pode contribuir a questões relacionadas à apropriação do espaço público; clandestinidade; práticas do cotidiano; informalidade; fiscalização e controle público.

Palavras Chave: Comércio ambulante, Ambulantes nos trens, Trem de São Paulo

\footnotetext{
1 Trabalho de conclusão de curso apresentado à Universidade Federal de São Paulo como requisito parcial para obtenção do título de Bacharel e Licenciatura em Ciências Sociais, Guarulhos, 2014. Orientado por Andréa Barbosa, coorientado por Marta Jardim, sob o parecer de Lindomar Albuquerque.

2 Universidade Federal de São Paulo, Guarulhos. Email: natalia.cruzdesouza@gmail.com
} 


\section{Introdução}

Este texto apresenta de maneira suscinta o trabalho de conclusão do curso de ciências sociais na Univerdade Federal de São Paulo sobre o tema do comércio ambulante nos trens de São Paulo. A investigação desenvolveu-se a partir do "estranhamento" do trem impulsionado pelo aviso eletrônico ao público durante a operação: "A CPTM informa: Pedir esmolas e o comércio ambulante são práticas ilegais. Não incentive essas ações".

A prática dita ilegal pela empresa ferroviária CPTM (Companhia Paulista de Trens Metropololitanos) é amparada pelo decreto $\mathrm{n}^{\mathrm{o}} 1.832$, de 4 de março de 1996, que aprova o regulamento dos transportes ferroviários, cujo anexo do regulamento dos transportes ferroviários Capítulo III, do transporte de passageiros, seção I, das condições gerais, dispõe:

Art. 40. É vedada a negociação ou comercialização de produtos e serviços no interior dos trens, nas estações e instalações, exceto aqueles devidamente autorizados pela administração ferroviária. (BRASIL, 1996)

A pesquisa norteou-se não nas definições legais, mas no cotidiano heterogênio e ambíguo dos trens da cidade de São Paulo, onde são articuladas práticas de convivência e sobrevivência na metrópole. Nesse cenário são tecidas relações efêmeras entre atores sociais que se identificam no espaço por sua prática: passageiros, comerciantes ambulantes, agentes de segurança e pedintes.

Das possíveis perguntas que são pertinentes ao entendimento desta atividade no transporte público, adentro na percepção da dinâmica singular deste comércio e seus aspectos. Como se faz para vender nesse espaço? O que inclui as práticas espaciais e as políticas de espaço. Como se vende em um espaço totalmente diverso? Incluindo a organização social da venda. 
Além da venda como troca, quais outras trocas? Refletindo a respeito das dinâmicas e os valores sociais envolvidos.

Entorno de questões de cunho político, econômico, e social, que tocam o tema, procuro através de uma perspectiva antropológica, perceber e analisar os aspectos antropológicos que fazem do espaço uma possibilidade ao comércio, e suas implicações. Para isso mobilizo uma literatura que toque o tema e/ou ajude a compreendê-lo com foco no repertório da antropologia urbana, pesquisa de campo e interacionismo simbólico.

\section{Objetivos}

A pesquisa foi construída com objetivo de evidenciar e analisar a dinâmica particular nesse transporte coletivo, um lugar em que transitam milhares de pessoas a todo tempo, para os mais variados destinos, possibilitando estratégias cotidianas de ações que visem à subsistência em meio à transgressão da regra.

Contudo, como objetivo geral viso ampliar o debate e abordagem da questão, sabendo sua importância contextual na atual dinâmica social do transporte coletivo, podendo contribuir a temáticas que aparecem como pano de fundo - a apropriação e privatização do espaço público; a ilegalidade; o direito à cidade; mobilidade urbana; práticas do cotidiano; informalidade; fiscalização e controle público.

Assim, os objetivos específicos são de problematizar a partir da abordagem antropológica e interacionista a percepção do comércio ambulante nos trens, venda não normatizada, a fim de compreender as relações de poder. Bem como, analisar a prática em contraste com outra também dita irregular no espaço, a mendicância, considerando as relações entre ambulantes e passageiros e pedintes e passageiros e algumas das 
possíveis interpretações cotidianas das práticas no limiar dos desejavéis, toleráveis, e, indesejáveis.

\section{Metodologia}

Parto do pressuposto de que é necessário produzir um conhecimento que transcenda a superficialidade dos discursos reproduzidos sobre os atores envolvidos. Assim, para a compreensão do tema realizei trabalho de campo na Linha 11 do trem de São Paulo, no trecho Luz a Guaianazes, atentando ao espaço e as relações sociais tecidas.

A partir do mapeamento dos atores sociais temos características importantes para analíse dessa atividade, demarcando as especificidades das relações travadas no espaço, onde a prática não é aceita por parte da autoridade, porém não necessariamente por parte de quem utiliza o serviço da empresa ferroviária, e, que também possivelmente consome produtos oferecidos pelos ambulantes.

A forma de pensar a pesquisa urbana admitida implica em uma compreensão "de perto e de dentro" (MAGNANI, 2002), que estabelece como método de trabalho a etnografia. Nesse sentido a abordagem etnográfica caracteriza a análise de maneira substancial, por sua relevância para um estudo microssociológico do assunto ainda pouco explorado em termos qualitativos.

\section{Discussão/ Resultados}

Durante a investigação, o comércio ambulante nos trens remetia a outras problemáticas, que procurei relacionar ao longo da pesquisa, questões sociais amplas de conflito, como o embate entre comércio estabelecido e o comércio 
ambulante; a venda formal e a informal; a superlotação, entre outros, visíveis na própria apropriação do espaço do trem.

Os primeiros passos asseguraram um reconhecimento geral do espaço e dos atores envolvidos, a fim de traçar e situar brevemente - uma preparação mínima para os passos seguintes. Os segundos passos, ao utilizar as observações e dados coletados em campo trouxe aspectos da interação no espaço, que, nortearam na perspectiva a respeito da permanência dos ambulantes nos trens.

A sociabilidade e o conflito e sua enunciação como cerne da pesquisa aos poucos foi se desenhando nas relações entre os atores. Uma das dificuldades de lidar com a temática é que, apesar de próxima aos moradores da cidade, é distante em termos de registros, por pertencer ao que é tido como marginal, informal, clandestino e ilegal, o que favoreceu o estudo de campo.

Aos ambulantes e seus produtos comercializados de vagão em vagão são atribuídos estigmas, uma maneira da autoridade de escapar do contato com o indesejável. Diante da ordem legislativa, e todos os esforços de extermínio da prática nos trens, a criminalização do grupo é um processo gradativo de expulsão que apresenta discrepâncias, pois, no convívio social a recepção dos passageiros é diferente, não somente por serem portadores de opiniões variadas a respeito, como também por nortearem seus critérios em concordância com o convívio, ora harmonioso, ora conflitivo.

Os ambulantes nos trens encontram os limites de sua prática nas relações de poder - ambulantes e agentes de segurança (representantes do aparelho repressivo do Estado), e, ambulantes e passageiros (seus clientes consumidores). Ora desejáveis, ora sujeitos a intolerância dos passageiros, os ambulantes conseguem permanecer no espaço reconhecendo as 
circunstâncias de risco e das oficialidades para o desenvolvimento de astúcias de autopreservação.

Como desviantes das regras expresso na mensagem auditiva ao público e cartazes institucionais, os atores envolvidos - pedintes e ambulantes - recorrem a estratégias diferentes de sobrevivência interpretadas pelos interlocutores, os passageiros. As práticas são interpretadas pelos passageiros segundo suas estratégias passíveis de discursos que reforcem as intencionalidades e que toquem moralidades diferentes entre pedir e vender. Contudo, a CPTM ao lutar pela implementação de suas regras pondera o papel dos passageiros de serem vigilantes cooperantes de sua política de erradicação de tais práticas.

\section{Referências}

AGUIAR, Ana Lídia de Oliveira . Entre o comércio informal e as margens do ilegal: Práticas de trabalho na rua 25 de março. 2013, 210 p. Tese de mestrado. Pós graduação em ciências sociais da Universidade Federal de São Paulo. Guarulhos, 26 de Agosto de 2013.

AUGÉ, Marc. Não Lugares: Introdução a uma antropologia da sobremodernidade. Lisboa: 90 Graus 2005, p. 07-96.

BECKER, Howard. "De que lado estamos?”. Uma teoria da Ação coletiva. Rio de janeiro: Zahar, 1977, p.122-136.

. Outsiders: Estudos de sociologia do desvio. Rio de janeiro: Zahar, 2008.

BOURDIEU, Pierre.O Senso Prático, Rio de Janeiro: Vozes, 2009, p. 133-226.

CALDEIRA, Teresa P. R. Cidade de muros: crime, segregação e cidadania em São Paulo. São Paulo: Companhia das Letras, 2000, p. 211-300.

CERTEAU, Michel. A invenção do Cotidiano. A arte de fazer. $12^{\mathrm{a}}$ Edição. Petropolis: Vozes, 1994, p. 91-117 e p.169-215.

DUMONT, Louis. "Genese, I: do Indivíduo-fora-do-mundo ao Indivíduo-no-mundo". O Individualismo: uma perspectiva antropológica da ideologia moderna. Rio de Janeiro, Rocco, 1985, p. 35-71. 
ELIAS, Norbert; SCOTSON, John L. Introdução. Ensaio teórico sobre as relações estabelecidos-outsiders: Sociologia das relações de poder a partir de uma pequena comunidade. Rio de Janeiro: Jorge Zahar, 2000.

FOUCAULT, Michel. Microfísica do poder. Rio de Janeiro: Graal, 2001. p. 179-191.

Os recursos para o bom adestramento; Ilegalidade e delinquencia. Vigiar e punir: história da violência nas prisões. Petrópolis: Vozes, 1999.

FRÚGOLI, Heitor. Centralidade em São Paulo: trajetórias, conflitos e negociações na metrópole. São Paulo: Cortez/ Edusp/ Fapesp, 2000. p. 69-103.

Espaços da cidade e atores sociais das ruas. Espaços públicos e Interação social. São Paulo: Marco Zero, 1995.

GEERTZ, Clifford. Interpretação das culturas. Rio de Janeiro, Zahar, 1978.

GOFFMAN, Erving. A Representação do Eu na Vida Cotidiano. Editora Vozes, 1985. . As características das instituições totais; Introdução; O mundo do internado.

Manicômios, prisões e conventos. São Paulo: Perspectiva, 1999. p.07-99.

LEACH, Edmund R. A diversidade na antropologia; O meu tipo de antropologia. A diversidade da antropologia. Lisboa, Edições 70, 1982.

MAGNANI, J. Guilherme; TORRES, Lilian (Orgs). Quando o campo é a cidade, fazendo antropologia na metrópole. Na metrópole: textos de antropologia urbana, São Paulo: Edusp/Fapesp. 2000.

MAUSS, Marcel. Ensaio sobre a dádiva.Sociologia e Antropologia. São Paulo: Cosacnaify, 2003, p.183-314

MISSE, Michel. Sobre uma sociabilidade violenta. Crime e violência no Brasil contemporâneo: estudos de sociologia do crime e da violência urbana. Rio de Janeiro: Lumen Juris Ed., 2011, p. 251-267.

PERALVA, Angelina. Violência e democracia: o paradoxo brasileiro. São Paulo: Paz e Terra, 2000, p. 17-127.

PIRES, Lenin. Esculhamba mas não esculacha! Uma etnografia dos usos urbanos dos trens da central do Brasil. 2011,171p. Tese de mestrado. Pós graduação em antropologia na Universidade Federal Fluminense. Niterói.

RABOSSI, Fernado. Nas ruas de ciudad del este: vidas e vendas num mercado de fronteira. Tese de doutorado. Pós graduação em antropologia social, Museu Nacional, Universidade Federal de São Paulo. Rio de Janeiro, dezembro de 2004.

SIMMEL, Georg. A metrópole e a vida mental. In VELHO, Otávio Guilherme (Org.). O fenômeno urbano. Rio de Janeiro: Zahar, $2^{a}$ Edição, 1973, p. 11 - 25. 
A natureza sociológica do conflito. In. FILHO, E. M. (Org.) Simmel. São

Paulo: Ática. 1983, p. 122-134.

VANDENBERGHE, Frédéric. As sociologias de Georg Simmel. Bauru, São Paulo: Edusc, 2005.

VELHO, Gilberto e KUSCHNIR, Marina. Pesquisas Urbanas: Desafios do trabalho antropológico, Rio de Janeiro: Jorge Zahar, 2003, p. 07-42.

Individualismo e Cultura: Notas para uma antropologia da sociedade contemporânea. Rio de Janeiro: Jorge Zahar, 2008, p. 122-134.

Observando o Familiar. In: NUNES, Edson de Oliveira. A Aventura

Sociológica. Rio de Janeiro, Zahar, 1978.

FONSECA, Claudia. Quando cada caso não é um caso. Revista Brasileira de Educação, nº10, 1999. Disponível em:

<http://educa.fcc.org.br/pdf/rbedu/n10/n10a05.pdf> Acesso em: 29 de outubro de 2012.

ITIKAWA, Luciana.Vulnerabilidades do trabalho informal de rua: Violência, corrupção, e clientelismo. São Paulo em Perspectiva. Volume 20, nº1, 2006, p.136147. Disponível em:

<http://produtos.seade.gov.br/produtos/spp/v20n01/v20n01_10.pdf> Acesso em: Março de 2013.

MAGNANI, José Guilherme. Da periferia ao centro: pedaços e trajetos. Revista de Antropologia, São Paulo, USP, v.35, 1992.

De perto e de dentro: Notas para uma etnografia Urbana. Revista Brasileira de Ciências Sociais, Volume 17, $\mathrm{n}^{\circ} 49$, Junho de 2002. Disponível em:<

http://www.scielo.br/pdf/rbcsoc/v17n49/a02v1749.pdf> Acesso em: 05 março de 2013.

MISSE, Michel. Mercados ilegais, redes de proteção e organização local do crime no Rio de Janeiro. Estudos Avançados, São Paulo, vol. 21, n. 61, 2007, pp. 139-157

Disponível em: <http://www.scielo.br/pdf/ea/v21n61/a10v2161.pdf> Acesso em: 13 de maio de 2013.

NEVES, Delma Pessanha. Os miseráveis e a ocupação dos espaços públicos. Caderno CRH, Salvador, n.30/31, p.111-134, jan/dez,1999. Disponível em:

<http://www.cadernocrh.ufba.br/viewarticle.php?id=235>. Acesso em: 23 de junho de 2013.

PEIRANO, Mariza. A favor da etnografia. Cadernos NAUI, serie antropologia.

Brasília, 1992. Disponível em: <http://naui.ufsc.br/files/2010/09/Peirano_a-favor-daetnografia.pdf> Acesso em: 29 de Outubro de 2012.

POCHMANN, Marcio et. al. Mapa do trabalho informal: Perfil socioeconomico dos trabalhadores informais na cidade de São Paulo, São Paulo: Fundação Perseu Abramo. 
Disponível em: 〈http://fpabramo.org.br/uploads/mapa_do_trabalho_informal.pdf> Acesso em: 20 de maio de 2013.

BRASIL. DECRETO n ${ }^{\circ} 1.832$, de 04 de março de 1996. Disponível em: <http://presrepublica.jusbrasil.com.br/legislacao/112337/decreto-1832-96>. Acesso em: 27 de fevereiro de 2014.

LUÍS, Pedro. Miséria S.A. Interprete: O RAPPA. In: Rappa Mundi. Rio de Janeiro: Warner Music, 1996. 1 Cd. Faixa 2. 04'”02'. 